\title{
Mudanças Climáticas e Movimentos Sociais do Campo
}

\author{
Climate Change and Rural Social Movements
}

\author{
Cambio Climático y Movimientos Sociales del Campo
}

João Vitor Gobis Verges ${ }^{1}$

João Osvaldo Rodrigues Nunes ${ }^{2}$

\begin{abstract}
RESUMO: As mudanças climáticas têm se colocado como temática importante da pauta política de inúmeros países. A partir das necessidades deste contexto, torna-se preciso compreender as diferentes alocações no assunto provindas de múltiplos atores em sociedade, buscando contribuir com a delimitação de ações públicas menos excludentes. Por este viés, objetivou-se com este trabalho evidenciar os contornos propositivos e combativos dispostos por movimentos sociais do campo sobre a temática "mudanças climáticas". Para isto, utilizou-se do aporte dialético para a análise de informações obtidas através de entrevistas com movimentos sociais, levantamento de dados em publicações científicas, mídias, preleções e informativos. Foram tomados como parâmetros três movimentos sociais significativos em escalas internacional e nacional, sendo eles: La Via Campesina; Movimento de Trabalhadores Rurais Sem Terra (MST); Movimento de Mulheres Camponesas (MMC). Concluí-se que tais agentes sociais se colocam como importantes atores na temática, com proposições definidas e diferenciadas das abordagens provindas dos principais protocolos globais. Desse modo, a não conjugação de suas indicações pode gerar marginalização e processos de exclusão nas formatações de agendas específicas sobre o tema.
\end{abstract}

PALAVRAS-CHAVE: Políticas públicas ambientais. Territorialidades. Inserções sociais.

ABSTRACT: Climate change has become an important issue on the political agenda of many countries. From the needs of this context, necessary is understand the different allocations in the subject coming from multiple actors in society, trying delimit public actions less excluding. From this bias, this paper aimed to highlight the contentious and combative contours arranged by social movements in the field on climate change. For this, the dialectical contribution was used for the analysis of information obtained through interviews with social movements, data collection in scientific publications, media, lectures and information. Three important social movements were taken as parameters in international and national scales, being: La Via Campesina; Movement of Landless

1 Doutor em Geografia pela FCT/UNESP - Presidente Prudente/SP e Doutor em Ciências do Ambiente pela Universidade de Lisboa. Docente e pesquisador do Instituto Federal de Mato Grosso (IFMT), Campus Avançado Guarantã do Norte, lotado no Departamento de Ensino. Av. Sen. Filinto Müller, 953 - Quilombo, Cuiabá - MT, 78043-400. vitorverges@gmail.com.

${ }^{2}$ Doutor em Geografia pela FCT/UNESP - Presidente Prudente/SP. Livre-Docente pela FCT/UNESP Presidente Prudente/SP. Docente e Pesquisador da FCT/UNESP, lotado no Departamento de Geografia. R. Roberto Símonsen, 305 - Centro Educacional, Pres. Prudente - SP, 19060-900. joaovaldo@gmail.com. 
Rural Workers (MST); Movement of Peasant Women (MMC). It is concluded that such social agents are important actors in the thematic, with defined and differentiated proposals of the approaches coming from the main global protocols. In this way, the non-conjugation of their indications may lead to marginalization and generate exclusion processes in the formatting of specific agendas on the topic.

KEYWORDS: Environmental public policies. Territorialities. Social insertions.

RESUMEN: Los cambios climáticos se han planteado como temática importante de la política política de numerosos países. A partir de las necesidades de este contexto, se hace necesario comprender las diferentes asignaciones en el asunto provenientes de múltiples actores en sociedad, buscando delimitar acciones públicas menos excluyentes. Por este sesgo, se objetivó con este trabajo evidenciar los contornos propositivos y combativos dispuestos por movimientos sociales en el campo sobre la temática cambios climáticos. Para ello, se utilizó el aporte dialéctico para el análisis de informaciones obtenidas a través de entrevistas con movimientos sociales, levantamiento de datos en publicaciones científicas, medios, prelecciones e informativos. Se tomaron como parámetros tres movimientos sociales significativos en escalas internacional y nacional, siendo ellos: La Vía Campesina; Movimiento de Trabajadores Rurales Sin Tierra (MST); Movimiento de Mujeres Campesinas (MMC). Se concluye que tales agentes sociales se plantean como importantes actores en la temática, con proposiciones definidas y diferenciadas de los enfoques provenientes de los principales protocolos globales. De este modo, la no conjugación de sus indicaciones puede generar marginación y procesos de exclusión en las formaciones de agendas específicas sobre el tema.

PALABRAS-CLAVE: Políticas públicas ambientales. Territorialidad. Inserciones sociales.

\section{INTRODUÇÃO}

Propõe-se com este artigo evidenciar o panorama político de inserção de movimentos sociais no campo, em escala global e nacional, dentro dos debates, ações e proposições sobre mudanças climáticas. Para isto, analisam-se três movimentos sociais referenciais, sendo eles: La Via Campesina; Movimento de Trabalhadores Rurais Sem Terra (MST); e Movimento de Mulheres Camponesas (MMC).

Tendo em consideração a importância e o significado das definições sobre os impactos das sociedades e economia à composição atmosférica e seu funcionamento, é relevante aplicar o discernimento das orientações políticas dispostas pelos movimentos sociais do campo, uma vez que este reconhecimento permite a compreensão das múltiplas vertentes territoriais, o que, em alargada medida, auxilia a clarificação de futuras proposições e projetos.

Desse modo, apresentam-se as constatações obtidas através do levantamento metodológico pautado na revisão bibliográfica e na obtenção de informações através das plataformas de comunicações dos movimentos sociais, preleções políticas e entrevistas. Abordou-se a questão pela verificação dialética e multiescalar, proporcionando uma 
exposição sobre as elucubrações no tema mudanças climáticas pelas abordagens internacionais e nacionais dos movimentos sociais do campo.

\section{ASPECTOS METODOLÓGICOS: MULTIESCALARIDADE E ESTUDOS DE CASO}

Este trabalho se fundamenta na análise do contexto político sobre mudanças climáticas, conjugando as interconexões escalares que o tema possui quando aproximado aos movimentos sociais do campo. Neste caso, apresenta uma configuração entre o global e o nacional, uma vez que as intencionalidades demarcadas em acordos internacionais possuem reverberações nas políticas internas dos países e, sobretudo, se efetivam (ou não) nas incumbências do cotidiano, em seus contornos como lugares e/ou territórios.

Dessa forma, a estruturação metodológica para compreender as extensões da questão climática se efetivou a partir da abordagem sobre os esquadros políticos predominantes dos processos sócio-históricos e geográficos sobre o tema. Para isto, foram realizados levantamentos bibliográficos e de dados primários em entrevistas com movimentos sociais, além de rede de dados em relatórios científicos publicados, mídias e fontes oficiais.

Adotou-se como mecanismo explicativo a formatação da investigação via "estudos de caso", apoiando-se nas indicações teóricas de Flyvbjerg (2006), em que as elucidações das narrativas explicativas sobre aspectos territoriais ficam bem evidenciadas a partir das constatações advindas de atores centrais. Tendo isto em vista, com a metodologia de concepção e definição dos estudos, expõem-se duas possibilidades de escolhas dos "casos": a) seleção aleatória; e b) informação - seleção orientada. Esta pesquisa ancorou-se na seleção orientada por informações previamente obtidas do recorte adotado (via estudos documentais e análises empíricas).

Dessa forma, foram elencados os seguintes movimentos sociais para o dialogo junto a agenda climática global e no Brasil: a agremiação internacional La Via Campesina, o Movimento dos Trabalhadores Rurais Sem Terra (MST) e o Movimento de Mulheres Camponesas (MMC). Adotam-se estes três exemplares como estudos de caso por possuírem inclinações e debates efetivos em torno das esferas das mudanças climáticas por atividades humanas. Além disto, representam uma totalidade de ação internacional (La Via Campesina) e, no caso do MST e MMC, estão em quase todos os estados brasileiros.

A centralidade das indicações interpretativas corresponde à medida multiescalar, de maneira que se observam as nuances interativas como processuais, não somente em termos de área. Assim, toda a conjuntura global-nacional possui conexões, uma vez que as escolhas e acontecimentos rebatem diretamente em diferentes alcances escalares. 
Dessa maneira, inicia-se a caracterização das propostas pelas constatações sobre como a agremiação La Via Campesina observa e atua no que corresponde às mudanças climáticas e, em sequência, apresentam-se as designações do MST e do MMC, permitindo traçar indicativos comparados e expressões para as considerações do trabalho.

\section{La Via Campesina e as mudanças climáticas}

A observação pelas miradas dos movimentos sociais no campo permite indicar apontamentos que possam contribuir positivamente com os processos em mitigações e adaptações relacionadas às mudanças climáticas, bem como colabora com a busca por diminuição das desigualdades sociais e da pobreza que predominam no cenário geral do cotidiano de vida destes agricultores.

Borras Junior, Edelman e Kay (2008) apontam que La Via Campesina é o maior movimento transnacional vinculado às dimensões agrárias, alocando a agremiação de diversos outros movimentos sociais, como o próprio MST e o MMC, caracterizando suas ações em várias abordagens. Desse modo, influencia mundialmente os debates sobre a reforma agrária, mas também apresenta proposições e indicativos de lutas nos projetos de sociedade e nas conformações das ações coletivas aportadas no cotidiano das populações que, em linhas amplas, possuem impactos escalares (sobretudo envolvendo dimensões ambientais).

Por este aspecto, vincula-se diretamente às acometidas ao amplo conceito de sustentabilidade, aportando em afirmativas não somente econômicas, mas sociais, políticas, culturais e ambientais, entendendo que as reivindicações dos agricultores familiares devem ser interpretadas e levadas em consideração nas políticas climáticas pela importância significativa desta parcela da sociedade nos desenhos agrários do Brasil e do mundo.

Tendo isto em vista, é possível delinear a reatividade concreta da Via Campesina, como um movimento social em macroescala, aos contributos das atividades diplomáticas em mudanças climáticas, provindas de Brasil, EUA, Japão e União Europeia, que resultaram em grandes acordos internacionais, emblematicamente, os casos do Mecanismo de Desenvolvimento Limpo (MDL), biocombustíveis e, posteriormente, a "Redução das Emissões por Desmatamento e Degradação Florestal" (REDD+). Como se pode perceber, o movimento expressa a seguinte posição:

"[...] denunciar las falsas soluciones que están proponiendo las transnacionales y los gobiernos de los países industrializados, como la agricultura climáticamente inteligente, el mercado de carbono, REDD, acaparamiento de tierras y la producción de agrocombustibles" (AGRICULTURA..., 2014). 
A Via Campesina entende que este complexo de medidas representa, em mesmo alcance, os efeitos e representações que a Revolução Verde possuiu no intervalo posterior a Segunda Grande Guerra, estendendo práticas conservadoras ao passo que propõe menores emissões de GEE (Gases de Efeito Estufa). Afirma que o processo de expulsão dos agricultores familiares, pela modernização da agricultura, é o mesmo em que se sugerem ações menos impactantes ao clima, o que denota o caráter ainda propagador de desigualdades sociais. Assim,

\begin{abstract}
Es el mismo que inició con la Revolución Verde y que sigue desarrollando pesticidas químicas, partiendo de las semillas híbridas, hoy las transgénicas; es el mismo proceso que está acaparando el Banco Mundial para desarrollar la agricultura industrial [...] es un engaño decir que con la agricultura climáticamente inteligente se va a resolver el hambre en el planeta y al mismo tiempo luchar contra el calentamiento global, cuando de hecho es simplemente una "cara modificada" de la agricultura industrial que va a seguir acaparando las tierras, acaparando el agua, la energía, entonces para producir menos. Es una forma de recolonización (AGRICULTURA..., 2014).
\end{abstract}

Como apontado por Porto-Gonçalves (2004) e Leff (2002), as buscas dos movimentos sociais no campo são pautadas na transcendência de uma lógica estritamente mercantilizada para configurar, largamente, uma racionalidade ambiental. De tal modo, "[...] pode-se caminhar no sentido de um modelo de sustentabilidade ecológica, uma sustentabilidade restrita, ou de sustentabilidades mais amplas, mais complexas, enfim, de racionalidades ambientais (sociedades-natureza)" (PORTO-GONÇALVES, 2004, p.227).

O que se materializa como contestação e questionamento é o fato de se "pintar de verde" a desigualdade e a injustiça nos acessos aos meios de obtenção de riquezas e manutenção das condições de vida digna ou, então, o proporcionar, de fato, a ampliação da reforma dos aportes desiguais no espectro rural.

O diálogo entre sustentabilidade restrita e ampla se apresenta profícuo neste processo, pois a injustiça social no Brasil tem sido "sustentada" há 500 anos, e a renovação/melhorias em termos de emissões de GEE nas mesmas práticas desenvolvidas, com semelhantes estruturas degradantes, não trará a sustentabilidade complexa (PORTOGONÇALVES, 2004).

Neste sentido, no domínio do questionamento aos contornos industriais da agropecuária, a Via Campesina reforça que a atividade primária nos desígnios dos cultivos vegetais e produção de animais é responsável por uma faixa entre $44 \%$ e $57 \%$ de todas as emissões de GEE no sistema alimentar global (LA SOBERANÍA..., 2014). Indo além, parcelarmente, entre $15 \%$ a $18 \%$ corresponderiam ao desmatamento, $11 \%$ a $15 \%$ processos agrícolas, $5 \%$ a $6 \%$ transportes, processamento e embalamento $8 \%$ a $10 \%$, refrigeração e comércio de $2 \%$ a $4 \%$ e desperdício de $3 \%$ a $4 \%$ (EL GRAN..., 2016). Como se aponta, "[...] 
é possível evitar impactos ambientais imediatos, mas com elevadíssima concentração de riqueza e poder, com um modelo ecologicamente sustentável e ambientalmente insustentável, posto que afirmando a injustiça social" (PORTO-GONÇALVES, 2004, p.227).

Por este viés, o movimento propõe cinco medidas para enfrentar as mudanças climáticas e alimentar com qualidade a população, alcances tais que não se alinham ao padrão geral das políticas sobre o mote e, pontualmente, da agenda brasileira no tema.

As estratégias corresponderiam a: 1) cuidar do solo; 2) cultivos naturais, sem químicos; 3) reduzir a quilometragem e focar em alimentos frescos; 4) restituir a terra aos agricultores familiares camponeses e destituir as megas-empresas; 5) não apresentar falsas soluções, mas sim o que funciona (LA SOBERANÍA..., 2014).

Basicamente, no que corresponde a 1) cuidar do solo, designa-se que as práticas camponesas gestadas durante gerações são capazes de reduzir os danos ascendidos em um século de agricultura moderna, que arrolaram uma perda entre $30 \%$ e $75 \%$ de matéria orgânica em terras aráveis. Como o movimento expõe:

Si a nivel mundial existieran las políticas correctas y los incentivos apropiados, se podrían recuperar los niveles de materia orgánica que existían en el suelo antes del advenimiento de la agricultura industrial (en unos 50 años, que más o menos corresponden al lapso de tiempo de su destrucción). Esto compensaría un $2430 \%$ de todas emisiones actuales de GEI (EL GRAN..., 2016).

Notado por Porto-Gonçalves (2004), além da perspectiva intrinsecamente ambiental, do desgaste dos solos, da utilização de agroquímicos, pesticidas, herbicidas e fertilizantes, ocorre que a análise histórica sobre a produtividade e a expansão de áreas de produções monocultoras apresenta, também, menor ampliação da oferta relativa de alimentos, de melhorias nas condições de vida do trabalhador rural e no preço do cultivo final.

Ao item 2) cultivos naturais, sem químicos, o movimento caracteriza que a utilização intensiva de produtos externos aos cultivos, bem como as atividades monocultoras, tornam a necessidade de uso dos defensivos cada vez mais elevada, isto por conta das pragas e insetos se volverem imunes e resistentes aos efeitos dos venenos, devendo estes se comporem sempre progressivamente (EL GRAN..., 2016). Assim, dispõem a produção pautada na agroecologia, assentada em não utilização de métodos ancorados em herbicidas e pesticidas, o que permite manter a biodiversidade e aumentar a matéria orgânica acumulada. Neste contexto, a Via Campesina afirma que:

El uso de químicos en las granjas industriales crece todo el tiempo, y los suelos se extenúan y las plagas y las yerbas se vuelven inmunes a los insecticidas y los herbicidas. No obstante, el campesinado en todo el mundo mantiene sus saberes y una diversidad de cultivos y animales para trabajar, productivamente, sin utilizar químicos. Diversifican sus sistemas con 
policultivos, integran la producción agrícola y animal, e incorporan árboles y vegetación silvestre. Estas prácticas aumentan el potencial productivo de la tierra porque mejoran la fertilidad de los suelos y evitan la erosión. Cada año aumenta la materia orgánica acumulada en el suelo, lo que hace posible producir más y más comida (EL GRAN...., 2016).

No que versa sobre o terceiro tópico 3) reduzir a quilometragem e focar em alimentos frescos, há um salto analítico na questão geográfica. O diálogo aqui se estabelece na contraposição entre os circuitos longos e curtos da economia, apontando as características essenciais a cada modalidade de trocas nas relações de produção e consumo.

Por esta via, estabelecer mercados distantes, sobretudo os vinculados à alimentação, é considerado amplamente irracional, pois se fundamenta no consumo de massa, apropriações culturais e intensa demanda por energia e simplificação de sistemas agrícolas. Além da própria redução da biodiversidade pela busca de elevada intensidade nos cultivos em monocultoras, ocorre a necessidade de ampliar continuamente o uso de agrotóxicos para a manutenção da produtividade e para a duração efetiva destes "alimentos" até a chegada ao destino global de seus mercados desde as suas origens.

Para além, Silveira et al. (2009) reforçam a ideia de que os circuitos curtos apresentam a dimensão de mercado como construção social, em que os sujeitos que negociam reconhecem suas estruturas vinculativas aos territórios a partir do conhecimento mútuo de práticas e intenções sociais, ambientais, culturais e produtivas. Fonseca, Almeida e Colnago (2009) caracterizam que nos circuitos curtos de produção e consumo os agricultores não se encaram numa ótica concorrencial, mas sim parceira, em que a experiência de cultivo e venda se amplia com a troca de saberes, sementes e técnicas, dentre outros. Notoriamente, a Via Campesina dispõe que:

La lógica corporativa que transporta alimentos por todo el mundo y de regreso, no tiene ningún sentido desde ninguna perspectiva. Este comerciar global que va del desmonte de vastos corredores de tierra y bosque para producir materias primas agrícolas de exportación a la venta de alimentos congelados en los supermercados, es el principal responsable de las emisiones de GEI procedentes del sistema alimentario. Este sistema podría reducir sus emisiones de GEI si la producción alimentaria se reorientara hacia mercados locales y alimentos frescos alejándose de la carne barata y la comida procesada. Lograrlo es, quizá, la lucha más dura de todas, porque las corporaciones y los gobiernos están muy implicados en expandir el comercio de alimentos y bebidas (EL GRAN..., 2016).

O quarto apontamento 4) restituir a terra aos agricultores familiares camponeses e destituir as mega-empresas expõe a situação de pobreza e descaso que se coloca como evidente na realidade cotidiana dos agricultores familiares e que se insere em suas buscas por contribuir positivamente com atividades correspondentes ao clima e produção. 
O que o movimento destaca é a massiva expansão de áreas monocultoras ligadas a grandes complexos agroindustriais, em que a produtividade, em si, é baixa quando comparada a dos agricultores familiares, e que recebem maiores atenções e condições de se estabelecerem economicamente, mesmo se aplicando em categorias sensivelmente degradantes em termos sociais e ambientais.

Com isso, percebe-se uma relação de defesa da ecologia em prol da produtividade de modo que não se aplique uma lógica estritamente mercantilizada, mas sim uma interação ecológica na qual o excedente do processo de conjugação positiva sociedade/meio é revertido em mercadorias. Dessa maneira, [...] meios e insumos são parte integrante do estoque disponível de capital ecológico. Não são adquiridos nos mercados como acontece na agricultura empresarial [...] (PLOEG, 2009, p. 20).

Esta crítica provinda do movimento transnacional se funda nos dados censitários dos principais países produtores de alimentos no mundo, em que a totalidade dos cultivos que chegam à mesa dos cidadãos provém da agricultura com base familiar. Isto fica muito bem apontado, com recorte particular, nos Censos Agropecuários do IBGE (2006), em que, como exemplo, no Brasil em média $87 \%$ da produção nacional de mandioca, $70 \%$ de feijão, $46 \%$ do milho, $38 \%$ do café, $34 \%$ do arroz e $58 \%$ do leite são oriundos da agropecuária com base familiar.

Desse modo, é sobretudo importante o acesso à terra e as condições de permanência nela com apoio efetivo e duradouro às atividades de produção de alimentos, tendo por base o acondicionamento ecológico da criação de animais e cultivo de vegetais. Neste feitio, políticas compensatórias apoiadas em caracteres do agronegócio são veementemente criticadas. Por este aspecto, a Via Campesina (LA SOBERANÍA..., 2014) apresenta que:

En los últimos cincuenta años, unos 140 millones de hectáreas - algo semejante a casi toda la tierra agrícola en India - fue acaparada por cuatro cultivos que sobre todo crecen en enormes plantaciones: soya, palma aceitera, canola y caña de azúcar. El área global donde se siembran estos cultivos (y otros como el maíz para fines industriales), que son todos notables emisores de gases con efecto de invernadero, crecerá si no cambiamos las políticas relacionadas. Hoy, los campesinos y pequeños productores se hayan apretujados en menos de una cuarta parte de toda la tierra agrícola, y no obstante continúan produciendo la mayor parte de los alimentos del mundo: $80 \%$ de la comida en los países no industrializados según dice la FAO. Los campesinos producen estos alimentos con mucho mayor eficiencia que las grandes plantaciones, y de modos mucho mejores para el planeta. La redistribución mundial de las tierras en beneficio de los pequeños agricultores puede reducir las emisiones de GEI a la mitad, en unas cuantas décadas, si se combina con políticas que les ayuden a reconstituir la fertilidad del suelo, y con políticas que fomenten el comercio local. 
Por fim, 5) não apresentar falsas soluções, mas sim o que funciona, corrobora nitidamente a visão de mundo e necessidades do movimento firmado em torno das óticas das pessoas que fazem a agricultura com base local, familiar e com menor capital, em que se busca afirmar as práticas culturais do lugar, em detrimento da pressão constante da economia global por espaços homogêneos e aptos ao processo de globalização.

Isto implica, de modo incisivo, na crítica ao modelo produtivo que exerce pressão sobre a geração e disposição de alimentos, seja no espaço direto do plantio da semente e da colheita, seja na transformação da matéria-prima na cadeia agroindustrial. Nos escritos da Via Campesina (LA SOBERANÍA..., 2014):

\begin{abstract}
Cada vez se reconoce más que los alimentos son centrales para el cambio climático. Los informes recientes del IPCC y las cumbres internacionales admiten que los alimentos y la agricultura son agentes importantes de emisiones de GEI y que el cambio climático implica tremendos retos para nuestra capacidad de alimentar a una población global creciente. No obstante, hay una nula voluntad política de desafiar el modelo dominante de producción y distribución industrial de los alimentos: los gobiernos y las corporaciones nos siguen proponiendo falsas soluciones. El cascarón vacío de la agricultura climáticamente inteligente no hace sino renombrar la Revolución Verde. Hay nuevas y riesgosas tecnologías como los cultivos con modificación genética para resistir la sequía o los proyectos de gran escala de la geoingeniería. Hay mandatos para producir agrocombustibles, lo que impulsa acaparamientos de tierra en el Sur. Están los mercados de carbono y los proyectos de REDD+, cuya esencia es permitir que los peores transgresores y contaminadores con GEl eviten la reducción de sus emisiones convirtiendo los bosques y tierras agrícolas de los campesinos y pueblos indígenas en parques de conservación y plantaciones. Ninguna de estas "soluciones" puede funcionar porque todas trabajan contra la única solución efectiva: hacer un viraje - del sistema agroalimentario industrial gobernado por las corporaciones, a los sistemas alimentarios locales que están en manos de las comunidades campesinas.
\end{abstract}

Como as dotações em alterações climáticas se baseiam em tecnologias, na maioria dos casos, voltadas às empresas com elevado capital e organização em escalas globais, os movimentos sociais entendem que ocorre um processo de exclusão firmado numa ideia compensatória também perversa, pois se utilizam das práticas camponesas e indígenas que preservaram as áreas naturais e suas potencialidades em biodiversidade e transformam isto em trunfo financeiro para continuar poluindo. Assim, incide um novo subjugo alicerçado em estruturas semelhantes ao colonialismo desenrolado entre os séculos XVI e XIX.

Estas contestações sobre o potencial conflito entre perspectivas para evitar grandes mudanças no clima e, ao mesmo tempo, duelos de projetos de desenvolvimento, também ficam muito bem expressas em representações artísticas nas publicações da Via Campesina, assim como se demonstra a seguir (figuras 1 e 2).

A partir destes tópicos e ampliando a análise que sintetiza a abordagem da Via Campesina no que tange à questão das mudanças climáticas, identifica-se que nos 
materiais publicados do movimento não se fazem questionamentos contrários ao Intergovernmental Panel on Climate Change (IPCC) e ao conceito de sustentabilidade, quando do tratamento da perspectiva das mudanças do clima, mas sim ao modelo de atuação do sistema econômico capitalista com anseios globais.

Figura 1 - Organismos geneticamente modificados

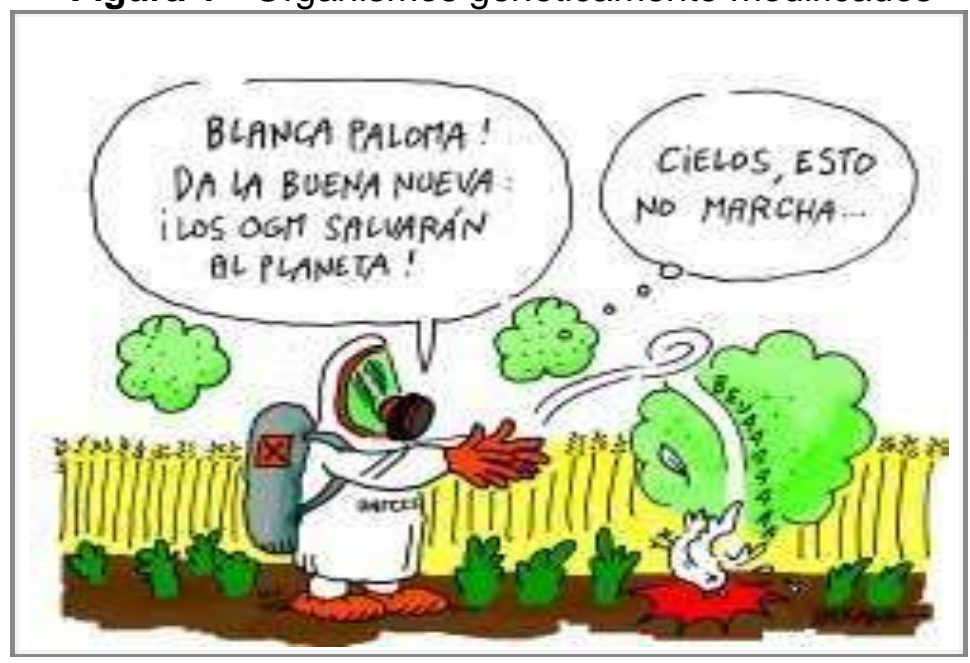

Fonte: (CLIMA..., 2016).

Figura 2 - Biocombustíveis

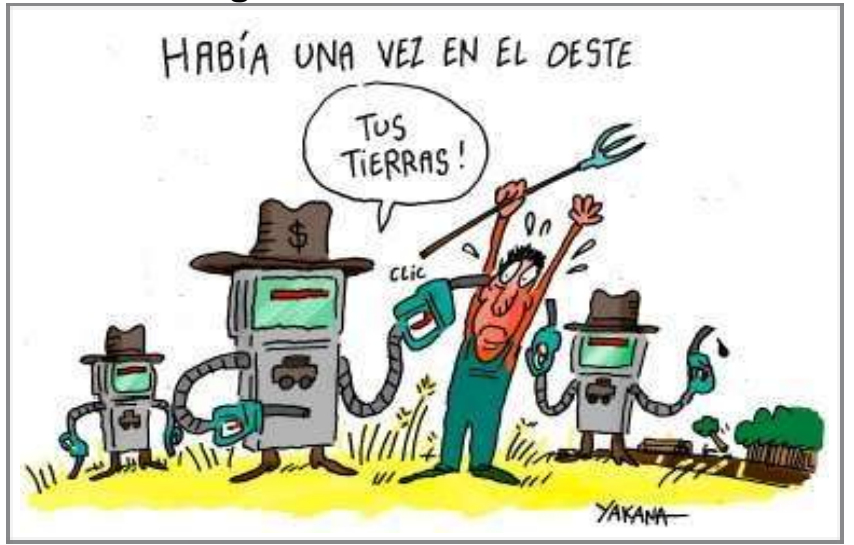

Fonte: (SEED..., 2015).

Por este viés, não há uma negação do assunto a partir de óticas voltadas a destituir a questão climática via mudanças antropogênicas, ou seja, decorridas das ações em sociedade, como ocorre em alguns espaços acadêmicos e do setor produtivo, mas sim uma busca por transgressão ao mainstream operante nos cultivos e criações com ligações aos grandes investimentos e propriedades de terras que rebatem em emissões de GEE.

Pode-se delimitar esta investida pela utilização argumentativa do movimento através dos dados do painel climático da Organização das Nações Unidas (ONU), constantemente apresentados para dar cabo da exposição da situação em que o planeta está posto pelas atividades humanas e com trechos em que, amplamente, o conceito de sustentabilidade se 
expressa em sua essência: "Con la agricultura campesina, recalcó, no solamente se producirá alimentos suficientes, sino también cuidar de la Madre Tierra, asegurar el porvenir de las generaciones futuras y al mismo tiempo enfriar al planeta" (LA SOBERANÍA..., 2014).

Neste contexto, instaura-se, então, uma disputa aos modos ou formatos dados aos meios de retração das ações humanas que impactam o clima, que privilegiam as grandes corporações e o modelo capitalista globalizante. As nuances que envolvem as caracterizações ambientais da sustentabilidade e das afirmações históricas, pelos contornos identificadores, via ONU e Organização Meteorológica Mundial (OMM) sobre o clima são corroboradas e utilizadas.

\section{A Via Campesina e as recentes contestações na COP-21/Paris}

Como meio ratificador das abordagens expostas sobre a Via Campesina e suas orientações políticas em relação ao clima e mudanças é pertinente a exposição e análise das manifestações do movimento transnacional da agricultura familiar na reunião da Conferência das Partes (COP-21) em Paris.

O movimento enfatiza, a partir de suas publicações, que por vários anos acompanha todas as realizações das COPs, promovendo um debate para além da superficialidade relativa ao alcance dos impactos que as mudanças climáticas podem trazer aos agricultores, mas estabelece que não corrobora certas proposições gestadas no seio dos diálogos na ONU sobre mitigação e adaptação ao tema. Como se observa, delimitam que:

En realidad, todos los campesinos y campesinas, independientemente de la región del mundo en la que vivan, son víctimas de los desajustes climáticos que impactan en sus prácticas cotidianas. También se han visto rodeados de falsas soluciones propuestas por las multinacionales y los gobiernos durante las conocidas Convenciones de las Partes (CENTENARES..., 2015).

Desde o início do encontro, no dia 4 de dezembro de 2015, os representantes da agricultura familiar estiveram reunidos em Paris para manifestar seus interesses e perspectivas, firmando que as práticas camponesas são as melhores indicadas para a questão climática global, e não a simples mercantilização em MDL e REDD das áreas preservadas por camponeses e indígenas.

Especificamente, delegados de 30 países estiveram presentes no continente europeu levando as bandeiras do movimento, sendo cinco africanos, um da América do Norte, quatro da América Central, três da América do Sul (dentre eles o Brasil), um do Oriente Médio, três da Ásia e treze da própria Europa (SEED..., 2015). 
Neste compasso, realizaram-se reuniões paralelas à COP, num espaço denominado Zona de Ação Climática (ZAC). Nele, os representantes da Via Campesina, bem como os sujeitos da sociedade civil que se interessaram em participar, tiveram a liberdade de expor suas perspectivas conceituais e propositivas relacionadas à temática. Assim, afere-se que a centralidade do debate esteve pautada na composição da soberania alimentar, na qual o agricultor domina a extensão da cadeia produtiva de seu cultivo e trabalha numa ótica agroecológica (circuitos curtos).

Largamente, denunciou-se que a COP não estava situada em propostas reais, pois denotara espaços expositivos aos sujeitos que não estão verdadeiramente interessados num futuro limpo (SEED..., 2015). Por exemplo, apresentou-se que em Uganda a pesca em pequena escala sofre com perseguições e proibições, enquanto as voltadas às grandes corporações recebem incentivos; a representante da Coréia do Sul ratificou que os acordos em livre comércio vêm depreciando a produtividade em pequena escala no país; e as empresas de mineração na Guatemala destroem áreas que dantes se prestavam à produção de alimentos (SEED..., 2015).

Por este caminho, incidem contestações que se colocam além de processos de mitigação e adaptação que se encaixam na mera geração de divisas e fomentação de um mercado global, assim como encontrado nos anseios dos protocolos das COPs. Existe um diálogo firmado concretamente no conceito de justiça, respeito às conformidades culturais e melhor acesso à riqueza e sua plena distribuição.

Outra especificidade interessante dos diálogos em Paris foi a seção denominada Asamblea de mujeres por el cambio del sistema y no del clima. Sob este título, apresentaram-se duas perspectivas interligadas, compondo uma totalidade: "o clima não deve mudar, mas o sistema que muda o clima sim". Dessa maneira, as articulações notoriamente pronunciadas em mercados globais são rejeitadas e vistas como mecanismos de perpetuar um código expurgador do agricultor familiar e, sobretudo, na visão feminina desta categoria, mecanismos que se apresentam também patriarcais.

Durante o evento, a Via Campesina, em associação com o sindicato francês de agricultores Confederation Paysanne, desenvolveu um protesto contra a empresa agroalimentar Danone, evidenciando sua luta contra os circuitos longos de produção e consumo de alimentos. Afirmam: "Esa organización defiende la agricultura sostenible a pequeña escala como un modo de promover la justicia social y la dignidad, y se opone firmemente a los agronegocios y las multinacionales que destruyen los pueblos y la naturaleza" (SEED..., 2015).

Como fechamento conclusivo sobre as notações da COP-21, a Via Campesina apresenta que a reunião se firmou como um "circo midiático" em que os principais beneficiários foram as multinacionais. Aportam aos debates climáticos entendendo que 
existem leituras paradigmáticas sobre as ações em mitigação e adaptação às mudanças no clima e que os países e seus representantes na ONU seguem as tendências neoliberais erguidas nos finais dos anos 1980 e desencadeadas largamente nos anos 1990. Como se observa,

\begin{abstract}
Sin embargo, a la hora de firmar acuerdos de libre comercio, ahí sí los Estados saben cómo hacer compromisos vinculantes. Esos acuerdos amenazan el funcionamiento democrático de los países con sólo servir a los intereses de las multinacionales. Una vez más, es evidente que el dinero dicta la ley, incluso con prioridad sobre el futuro de la humanidad. Los campesinos de todo el mundo, de las organizaciones miembros de Vía Campesina, se reunieron para advertir a los demás de que el sector agrícola está siendo severamente afectado. Mientras que ellos son los guardianes de un clima cambiante, ellos subrayan que la agricultura industrial los amenaza de desaparición. Al mismo tiempo, la COP21 está abriendo más la puerta a la especulación financiera sobre la naturaleza, la industrialización de la agricultura, y la aceleración del acaparamiento de recursos. Nosotros, los campesinos del mundo, ahora volveremos a nuestros territorios y fincas aún más decididos a seguir nuestra lucha por la soberanía alimentaria por todos los pueblos del mundo (SEED..., 2015).
\end{abstract}

Assim sendo, igualmente pertinente se apresenta realizar uma análise sobre como os movimentos sociais brasileiros, inseridos nos diálogos da Via Campesina, carregam consigo estes debates sobre as mudanças climáticas. Para isto, o artigo inclina-se para a compreensão das orientações em Climate Change nas óticas de dois movimentos significativos no Brasil: o MST e o MMC. De acordo com Fernandes (2004, p. 278), o MST desenvolveu organizações em todos os estados brasileiros, sendo o movimento com maior pujança nas questões agrárias do país. Neste âmbito,

Desde 1985, quando o MST se territorializou por todas as regiões do Brasil, os sem-terra intensificaram as ocupações, causando grande impacto político, de modo que passaram a ser os principais interlocutores no enfrentamento com 0 Estado, na luta pela terra e pela reforma agrária. Esses trabalhadores de origem rural ou urbana estão lutando pela terra em todas as grandes regiões.

Já o MMC, assim como expõem Carneiro (1994), Sales (2007) e Paulilo e Silva (2007), representa a formatação de uma nova identidade das lutas no campo, que além de afrontar os intentos hegemônicos das grandes formas capitalizadas da economia, buscam a afirmação da igualdade social na perspectiva do gênero.

Durante toda a luta dos movimentos sociais, como o próprio MST, a força das mulheres sempre esteve disposta e aplicada ao trabalho rural e político, porém distanciada da importância social que possui e sempre relativizada. Neste sentido, dá-se voz a uma importante parcela de representantes dos movimentos sociais no campo, que são as mulheres, e se expõe suas perspectivas concretas sobre o clima e mudanças. 


\section{Movimento dos Trabalhadores Rurais Sem Terra (MST) e Movimento de Mulheres Camponesas (MMC): a questão climática}

O MST relata sua inclinação ao mote das mudanças climáticas a partir da contestação aberta sobre o agronegócio. Para o movimento, este modelo de se concretizar as atividades no campo é o "grande vilão" do aquecimento global em atividades realizadas no Brasil. "No caso brasileiro em específico, o agronegócio será denunciado como um dos principais responsáveis pelas mudanças climáticas no país [...] Se o agronegócio fosse um país, ele seria o $10^{\circ}$ maior emissor de gases de efeito estufa do mundo" (MST, 2014).

Isto denota a clara conformação combativa histórica entre os agricultores familiares e a estrutura conflituosa do campo brasileiro, no qual houve a massiva destinação de recursos e projetos aos grandes proprietários de terras, construindo um perfil desigual na economia e sociedade a partir das designações estruturais da Revolução Verde e a modernização da agricultura. Para além, significa outra face das implicações combativas dos movimentos sociais, em que se posiciona o debate para enfoques mais amplos que a própria obtenção de terras para o trabalho, direcionando a mirada aos "modos" e ao "futuro".

Como contestação inerente a este caminho, afere-se igualmente a manifestação contrária à circulação global da economia, em circuitos longos, o que traz consigo enormes gastos em combustíveis e a necessidade de pacotes tecnológicos que sustentem as manifestações simplificadoras dos agroecossistemas. $O$ ataque deste modelo de produção à biodiversidade é muito exposto pelo movimento. Especificamente, sobre o agronegócio em larga escala e as ocorrências em mudanças climáticas, tem-se:

Isso, graças ao seu modelo produtivo, como a produção em larga escala que contribui com o desmatamento de todos os biomas brasileiros, a pecuária extensiva responsável pela emissão de metano e a enorme utilização de agrotóxicos que contaminam o solo, os lençóis freáticos, rios e aquíferos (MST, 2014).

Dentro das publicações expostas pelo MST, verificam-se conteúdos combativos no cotidiano de diários e jornais e a demonstração teórica de suas abordagens em clima e mudanças a partir da vinculação entre pensadores especialistas no tema e as bandeiras do movimento. Assim, explanam o alinhamento conceitual em relação à temática e, ao mesmo tempo, a criação justificada de argumentos sobre a potencialização do mal causado pelas atividades produtoras, sobretudo, de commodities. A busca se dá por outro padrão de desenvolvimento, com inserção das propostas provindas dos agricultores familiares. 
Neste sentido, adotam que não se pode confiar em soluções únicas para a questão agrária, como os biocombustíveis projetados no país, principalmente pela expansão do uso do Etanol misturado à gasolina. Largamente, apontam que este modelo transforma a terra e seu uso unicamente em mercadoria, substituindo áreas de produção de alimentos por especulações dos ramos energéticos e, em linhas gerais, pelas próprias intencionalidades dos mercados de emissões criados através de mecanismos MDL e, recentemente, REDD.

Associadamente há o destaque para a produção camponesa justamente pela dissociação com a demanda por combustíveis fósseis e o largo uso de agroquímicos na determinação da produção moderna da agricultura, das inferências ao clima e na obtenção geral da produtividade. Dessa maneira, a agricultura com base familiar, com menor utilização (ou nenhuma) de aparatos provindos de combustíveis fósseis no momento da produção, consegue obter maior numerário relativo quando da comparação com sistemas monocultores em larga escala. E neste sentido, dispõem:

\begin{abstract}
A enorme maioria dos governos de todo o mundo ignorou os produtores de pequena escala durante décadas, afundando milhões deles na pobreza. Entretanto, esses camponeses e camponesas continuam sendo os que produzem a maior parte dos alimentos do mundo, utilizando variedades tradicionais de sementes e sem recorrer a insumos industriais. Na África, os camponeses cultivam praticamente todos os alimentos consumidos localmente. Na América Latina, $60 \%$ da produção, incluída a carne, é produzida em pequenas propriedades familiares. Na Ásia, centro mundial da produção de arroz, praticamente todo o arroz é cultivado em áreas inferiores a dois hectares. Mesmo assim o agronegócio e alguns governos promovem fortemente a agricultura industrial (baseada em monoculturas, sementes híbridas e pesticidas e fertilizantes químicos) como a melhor forma de alimentar o planeta. Além disso, a agricultura industrial é uma das maiores contribuintes para a mudança climática, devido ao seu alto consumo de combustíveis fósseis, pesticidas e fertilizantes e por seus impactos sobre solos, águas e biodiversidade (CHANDRASEKARAN; DRAGO, 2014).
\end{abstract}

De forma associada, o MST corrobora a destruição dos recursos naturais pela indústria de alimentos, apresentando que:

[...] existe suficiente evidência de que essa indústria está destruindo os recursos dos quais dependemos para produzir nossos alimentos. Porém, os promotores da agricultura industrial fazem caso omisso de seus impactos ambientais. Conhecendo o grande desafio que representa a mudança climática, já que poderia reduzir consideravelmente a produtividade agrícola, especialmente nos países em desenvolvimento, outros são os caminhos que se deveria fomentar (CHANDRASEKARAN; DRAGO, 2014).

O contexto argumentativo do movimento se dispõe na estruturação de ações correspondentes à temporalidade e necessidades contemporâneas, inseridas nos intercursos da virada do século XX para o XXI. Por este viés, as dotações contestadoras 
ultrapassam questões primárias, como a busca por onde trabalhar e a posse dos instrumentos laborais, mas sim por direcionamentos políticos e institucionais que representam as causas e anseios de uma parcela social que reivindica o domínio de suas trajetórias. Como afirmado por João Pedro Stédile - representante nacional do MST - ao jornal "Carta Maior" em 2014:

No século passado, a reforma agrária respondia a uma necessidade de democratizar a propriedade da terra. A luta principal, portanto, era contra o latifúndio, em geral improdutivo. De um modo geral, esse programa de reforma clássico ocorreu no âmbito de governos burgueses nacionalistas. No Brasil, nunca conseguimos fazer esse tipo de reforma agrária. O mais próximo disso ocorreu na crise de 64, com a proposta de reforma do Celso Furtado- Goulart. O MST se desenvolveu com base nesse programa, de terra para quem nela trabalha. Infelizmente, ele não se realizou no Brasil. Agora, com o capitalismo financeiro e as corporações transnacionais dominando a agricultura, a disputa não é apenas por terra. A disputa é pelo modelo de produção agrícola. A disputa é pelo destino dos recursos naturais. Precisamos mudar o modelo (STÉDILE..., 2014).

Complementarmente, buscando ratificar as informações sobre as novas demandas por partes dos movimentos sociais do campo, Stédile expõe:

\begin{abstract}
Em primeiro lugar, para produzir alimentos sadios a toda sociedade. Comida sem veneno. Ao mesmo tempo, adotar a matriz tecnológica da agroecologia: produzir em equilíbrio com a natureza, sem destruir a biodiversidade que altera o meio ambiente e o clima. E precisamos organizar agroindústrias na forma cooperativa, para processar esses alimentos. Por isso, agora estamos diante de um novo modelo que chamamos de reforma agrária popular. Essa é uma bandeira que não interessa apenas ao camponês, que antes queria apenas terra para trabalhar. Agora, as mudanças, interessam a todo povo. Interessa a quem não quer adoecer ou morrer de câncer por conta da ingestão de agrotóxico, que tem no Brasil o maior consumidor mundial. Interessa aos que sofrem na cidade, expulsos do campo; e aos que se preocupam com a desordem climática em curso, como o demonstra a falta de água em São Paulo. Esse será o futuro da agricultura, e na verdade, a única possibilidade de sobrevivermos (STÉDILE..., 2014).
\end{abstract}

Neste cenário, é possível compreender que o MST corrobora as afirmações da Via Campesina no que corresponde às mudanças climáticas, figurando um alinhamento conceitual que reforça as ações transnacionais realizadas em macroescala. Mormente, a dotação é por um modelo de desenvolvimento que compreenda as indicações produtivas dos agricultores familiares, de maneira que estas possam contribuir positivamente com as questões climáticas nacionais e globais.

No que corresponde ao MMC, em entrevista realizada por nós no início de $2015^{3}$, as implicações do movimento se apresentam de maneira generalista, em que há o alinhamento

\footnotetext{
${ }^{3}$ Entrevista realizada pelos autores com o MMC, no início de 2015.
} 
com a nomeação diferenciada a partir das responsabilidades históricas dos países, entendendo a questão também como geopolítica. Sobretudo, o posicionamento central demarca a inerência de uma política global sobre o clima, mas que preserve em si as facetas em encargos por atuações previamente construídas nos âmbitos econômicos das nações, levando em consideração as pluralidades de atores sociais e suas condições sóciohistóricas.

Por este caminho, o movimento busca se alinhar as mediações transnacionais da Via Campesina, caracterizando um contraponto notório às indicações mercadológicas e majoritariamente voltadas aos cultivos monocultores e em grande escala apoiados pelos acordos globais, considerando as múltiplas vertentes em encargos e compromissos com o clima e mudanças. Como ressaltam,

Os efeitos das mudanças climáticas não são barrados pelas fronteiras políticas e geográficas dos Estados Nacionais, nem dos continentes, assim como, as políticas e modelos de desenvolvimento adotadas por determinado pais, que terão consequências no âmbito ambiental e, por conseguinte reflexos nas questões climáticas não afetarão apenas aquele país, mas pode ter reflexos em qualquer outro lugar do mundo. E partindo desta reflexão, sabemos que a responsabilidade histórica em relação às mudanças climáticas não é igual para todas as nações, os países do Norte possuem uma divida elou pegada ecológica muito maior que os países do Sul, pelo seu papel como países colonizadores, exploradores e que começaram a destruição e contaminação no processo industrial há muito mais tempo que os países dos Sul. Sendo assim, as políticas de responsabilidade devem ser globais, mas diferenciadas em termos do papel que cada pais teve e tem na historia das mudanças climáticas.

Ampliando a questão, o próprio MMC apresenta que neste entremeio climático a perspectiva escalar é central, expondo que a função dos indivíduos é essencial na coletividade do assunto, mas que, associadamente, os projetos de desenvolvimento dos países contam notoriamente com os direcionamentos para a aplicação efetiva de ações em mitigação e adaptação.

Neste aspecto, o padrão de desenvolvimento ancorado nas vias únicas de mercado é contrariado por seus caracteres históricos de expropriações e marginalizações. Conjuntamente, aparece a faceta agroexportadora (circuitos longos) como responsável pela ampla demanda em energia e por consumir os recursos naturais de maneira demasiada. Como se observa,

Para o movimento as mudanças climáticas são resultado do modelo de desenvolvimento explorador, contaminador e destrutivo do capital, baseado no lucro acima da natureza e das pessoas, em especial do modelo agroexportador do agronegócio. E neste sentido, para nós a agroecologia é o sistema de produção e de vida no campo contra hegemônico ao agronegócio que garante a produção de alimentos saudáveis, de qualidade e diversificados, de uma forma harmônica com a natureza, garantindo a 
conservação da biodiversidade e da agrobiodiversidade local, conservando e multiplicando as sementes crioulas, produzindo sem o uso de agrotóxicos e transgênicos que contaminam e destroem a vida do solo, das águas e do ar.

Complementando, em termos de responsabilidades pontuais sobre as ações para a contenção de emissões de GEE, partindo das mudanças de paradigmas produtivos nos âmbitos especificamente rurais, o MMC denota que existe uma inter-relação entre as ações sociais junto ao clima que perpassam a sociedade em sua totalidade, desde o indivíduo até os projetos de desenvolvimento, tendo o Estado como o guia, gerador de normas e fiscalizador das práticas tomadas nos âmbitos públicos e privados.

O MMC entende que o papel de regulação e normatização das questões climáticas parte do Estado, mas que este deve considerar a realidade em suas várias faces, com os muitos agentes sociais que a compõem, ou seja, compreender que existem perspectivas territoriais formadas no seio estruturante do país e que a agenda climática deve se centrar na articulação de tais atores para o desenvolvimento. Assim, tem-se que:

A responsabilidade é de toda a sociedade, setor publico e privado, porem não pode ser diminuída a responsabilidade de cada indivíduo, é uma responsabilidade do modelo de desenvolvimento adotado por cada pais, e deve ser incumbência dos países buscar formas e/ou políticas de mitigação $e$ adaptação às mudanças climáticas e garantir a implementação e cumprimento das mesmas pelos estados, municípios, setor privado e população.

Para o MMC, toda a sociedade é responsável pelas atribuições de contrapartidas para a proteção, ou menor impacto, no sistema climático, impactos que venham a prejudicar a coletividade como um todo. Largamente, entende-se que os projetos de desenvolvimento nacionais é que orientam as medidas em relação às mudanças no clima, mas que a tomada de ações pela sociedade em totalidade, dos indivíduos aos arquétipos produtivos, deve ser um guia essencial para o cumprimento de metas e diretivas organizadas pelo Estado.

Vastamente, o reconhecimento das práticas providas da agricultura familiar é, também, um dos trilhos do questionamento às diretivas em mudanças do clima. De maneira notória, se perguntam: por que motivos não existem grandes diretivas aos produtores de alimentos em circuitos curtos de produção, ou, ao menos, o reconhecimento de suas potencialidades como meios de contenção de GEE? O reconhecimento desta parcela da sociedade e seus projetos é um elemento balizador nas contestações em relação à política e clima. Neste caso, o MMC dispõe:

Acreditamos que o Estado deve reconhecer o papel dos camponesas/as, indígenas, quilombolas e comunidades tradicionais na preservação e cuidado com o meio ambiente, a biodiversidade e a produção de alimentos, 
e para isso deve garantir políticas publicas que proporcionem a agricultura camponesa e a agroecologia como forma de produção agrícola e agropecuária e a comercialização desta produção. Mas sem cair na perspectiva de programas como o Pagamento por Serviços Ambientais ou projetos de REDD+, que são formas de pagar aqueles/as que sempre preservaram a natureza para que outros, em especial empresas poluidoras e grandes produtores do agronegócio, sigam destruindo e poluindo a natureza, são formas do capital financeiro se apropriar e mercantilizar os territórios, os bens comuns e os saberes tradicionais que ate o momento não estão sob controle do mercado.

Assim sendo, o papel do Estado, de acordo com o MMC, é o de dimensionar as atividades sobre mudanças do clima de maneira que enquadrem os prismas dos agricultores familiares, estruturando medidas para além das organizadas em conformações para o mercado externo e compra e venda de emissões de GEE.

Desse modo, é possível compreender que os movimentos sociais no Brasil, tendo como representações emblemáticas o MST e o MMC, corroboram a Via Campesina e criam, numa totalidade escalar nacional e transnacional, um contra-projeto, ou contra-discurso, dos principais ordenamentos em mudanças climáticas observados nos diálogos globais sobre o assunto.

\section{CONSIDERAÇÕES FINAIS}

Os movimentos sociais no campo analisados, em suas atuações escalares internacionais e nacionais, evidenciam determinadas negações aos projetos firmados e contemplados pela "questão climática" mundial, o que não caracteriza o distanciamento deste escopo, ainda mais na esfera pragmática das representações e intentos de boa parcela dos agricultores familiares, mas sim no posicionamento assimétrico.

Nisto, aspectos ligados aos projetos em MDL são dificultados, negados e combatidos pelos movimentos sociais, ratificando a necessidade de amplo diálogo territorial sobre a abordagem climática e as ações em mitigação, adaptação e resiliência. Assim, as inclinações políticas dos movimentos não negam ou diminuem a questão climática, envolvendo-se com consignações derivadas da noção de sustentabilidade, o que implica a necessidade contínua de observações sobre suas considerações e propostas no assunto.

Dessa forma, procurou-se com o trabalho expor alíneas das compreensões sobre mudanças climáticas por parte de importantes atores sociais do campo brasileiro e com ligações em esferas nacionais. Com isto, o trabalho fomenta futuras perspectivas críticas com relação à construção de estudos e políticas que envolvam a globalidade do tema.

Paralelamente, indica-se o preenchimento de lacunas na compreensão sobre os impactos gerados nos instrumentos públicos que se referem às mudanças climáticas por 
parte das ações políticas dos movimentos sociais do campo, discernindo, assim, aspectos territoriais do processo combativo entre projetos de desenvolvimento.

\section{REFERÊNCIAS}

AGRICULTURA campesina vs. agricultura climáticamente inteligente. 2014. Disponível em: <https://viacampesina.org/es/agricultura-campesina-vs-agricultura-climaticamenteinteligente/>. Acesso em: 15 fev. 2016.

BORRAS JUNIOR, S. M.; EDELMAN, M.; KAY, C. Transnational agrarian movements: Origins and politics, campaigns and impact. Journal of Agrarian Change, Oxford, v. 8, n. 23, p. 169-204, 2008.

CARNEIRO, M. J. Mulheres no campo: notas sobre sua participação política e a condição social do gênero. Estudos Sociedade e Agricultura, Rio de Janeiro, n. 2, p. 11-22, jun. 1994.

CENTENARES de campesinos del mundo movilizados para la COP21. 2015. Disponível em: <https://viacampesina.org/es/centenares-de-campesinos-del-mundo-movilizados-parala-cop21/>. Acesso em: 8 set. 2015.

CHANDRASEKARAN, K.; DRAGO, M. A agroecologia é a solução para a fome e a mudança climática. 2014. Disponível em: <http://www.mst.org.br/2014/12/04/aagroecologia-e-a-solucao-para-a-fome-e-a-mudanca-climatica.html>. Acesso em: 15 maio /2016.

CLIMA: problema verdadero, falsas soluciones: transgénicos. 2015. Disponível em: <https://viacampesina.org/es/clima-problema-verdadero-falsas-soluciones-1-transgenicos/>. Acesso em: 1 fev. 2016.

EL GRAN robo del clima. Por qué el sistema agroalimentario es uno de los motores de la crisis climática y qué podemos hacer al respecto. 2016. Disponível em:

<http://editorialitaca.com.mx/wp-content/uploads/2017/04/El_gran_robo_del_clima.pdf> Acesso em: 16 maio 2016.

FERNANDES, B. M. Espaços agrários de inclusão e exclusão social: novas configurações do campo brasileiro. Agrária, São Paulo, SP, v. 1, p. 16-36, 2004.

FLYVBJERG, B. Five misunderstandings about case-study research. Qualitative Inquiry, London, n. 2, v. 12, p. 219-245, Apr., 2006.

FONSECA, M. F. A. C.; ALMEIDA, L. H. M.; COLNAGO, N. F. Características, estratégias, gargalos, limites e desafios dos circuitos curtos de comercialização de produtos orgânicos no Rio de Janeiro: as feiras. Cadernos de Agroecologia, Rio de Janeiro, v. 4, n. 1, p. 25992602, 2009.

IBGE. Censo agropecuário 2006: resultados preliminares. Rio de Janeiro, 2006.

LA SOBERANÍA alimentaria: 5 pasos para enfriar el planeta y alimentar a su gente. 2014. Disponível em: <https://www.grain.org/es/article/entries/5100-la-soberania-alimenta?print=true >. Acesso em: 30 jul. 2015. 
LEFF, E. Saber ambiental: sustentabilidad, racionalidad, complejidad, poder. São Paulo: Siglo XXI, 2002.

MST. Movimento dos Trabalhadores Rurais Sem Terra. Mobilização contra mudanças climáticas terá bloco 'Não Vote em Ruralista", no Rio. 2014. Disponível em:

<http://www.mst.org.br/2014/09/19/mobilizacao-contra-mudancas-climaticas-tera-bloco-naovote-em-ruralista-no-rio.html> Acesso em: 14 maio 2016.

PAULILO, M. I.; SILVA, C. B. da. A luta das mulheres agricultoras: entrevista com Dona Adélia Schmitz. Revista Estudos Feministas, Florianópolos, v. 15, n. 2, p. 399-417, 2007.

PLOEG, J. D. Sete teses sobre a agricultura camponesa. In: PETERSEN, P. (Org.).

Agricultura familiar camponesa na construção do futuro. Rio de Janeiro: AS-PTA, 2009. p. 17-32.

PORTO-GONCALVES, C. W. Geografia da riqueza, fome e meio ambiente: pequena contribuição crítica ao atual modelo agrário/agrícola de uso dos recursos naturais. Revista Internacional Interdisciplinar INTERthesis, Florianópolis, v. 1, n. 1, p. 1-55, 2004.

SALES, C. M. V. Mulheres rurais: tecendo no mulheres rurais: tecendo novas relações e reconhecendo ações e reconhecendo direitos. Revista Estudos Feministas, Florianópolis, v. 15, n. 2, p. 437-443, 2007.

SEED laws that criminalise farmers: resistance and fightback. 2015. Disponível em: <https://www.grain.org/article/entries/5142-seed-laws-that-criminalise-farmers-resistanceand-fightbac>. Acesso em: 12 abr. 2015.

SILVEIRA, P. R. C. et al. Construção dos mercados na produção artesanal de alimentos: os circuitos curtos de comercialização. In: CONGRESSO BRASILEIRO DE SOCIOLOGIA, 14., 2009, Rio de Janeiro, RJ. Anais... Rio de Janeiro: SBS, 2009. p. 1-20.

STÉDILE: Lula percebeu o fim de um ciclo e a necessidade de avançar. Carta Maior, São Paulo, 2 out. 2014. Política. Disponível em:

<http://www.cartamaior.com.br/?/Editoria/Politica/Stedile-Lula-percebeu-o-fim-de-um-ciclo-ea-necessidade-de-avancar/4/31917> Acesso em: 12 abr. 2016.

\section{Agradecimento}

À Coordenação de Aperfeiçoamento de Pessoal de Nível Superior (CAPES) e ao Instituto Federal de Educação, Ciência e Tecnologia de Mato Grosso (IFMT).

Recebido: junho de 2017.

Aceito: junho de 2018. 